\title{
Demanda hídrica da cana-de-açúcar, por balanço de energia, na microrregião de Teresina, Piauí
}

\author{
Aderson Soares de Andrade Junior ${ }^{1(*)}$, Donavan Holanda Noleto ${ }^{2}$, Edson Alves Bastos ${ }^{3}$, Magna Soelma Beserra de Moura ${ }^{4}$, \\ João Carlos Rocha dos Anjos ${ }^{5}$ \\ ${ }^{1}$ Pesquisador, Embrapa Meio-Norte, Teresina, PI, aderson.andrade@embrapa.br \\ ${ }^{2}$ Mestre em Engenharia Agrícola, UFC, Fortaleza, CE, donavan.noleto@outlook.com \\ ${ }^{3}$ Pesquisador, Embrapa Meio-Norte, Teresina, PI, edson.bastos@embrapa.br \\ ${ }^{4}$ Pesquisadora, Embrapa Semiárido, Petrolina, PE, mgna.moura@embrapa.br; 5Professor, UFPI, Bom Jesus, PI, joaocarlosrochadosanjos@hotmail.com \\ ${ }^{(*)}$ Autor para correspondência
}

\section{INFORMAÇÕES}

História do artigo:

Recebido em 16 de Junho de 2017

Aceito em 10 de agosto de 2017

Termos para indexação:

Saccharum officinarum L.

coeficiente de cultura

razão de Bowen

\section{RESUMO}

O objetivo deste estudo foi quantificar a demanda hídrica da cana-de-açúcar, por meio do método de balanço de energia (razão de Bowen), na microrregião de Teresina, Piauí. O experimento foi conduzido na Usina COMVAP, na microrregião de Teresina, Piauí. A cultivar utilizada foi a RB867515, irrigada por pivô central. Para a estimativa de evapotranspiração da cultura (ETc) usou-se uma torre equipada com sensores microeletrônicos instalada no centro de um talhão de 10 ha. A evapotranspiração de referência (ETo) foi estimada pelo método Penman-Monteith. A análise de consistência física dos dados de ETc mostrou que 33,9\% dos 406 dias monitorados foram consistentes. A ETc média diária foi de 5,3 $\mathrm{mm}$, totalizando uma demanda de $2.650 \mathrm{~mm}$, para os 498 dias do ciclo. O coeficiente de cultivo (Kc) médio por fase foi de 0,9 (crescimento rápido), 1,32 (máximo desenvolvimento) e 1,07 (maturação).

(c) 2017 SBAgro. Todos os direitos reservados.

\section{Introdução}

O Brasil destaca-se como maior exportador de açúcar e etanol, provenientes da cana-de-açúcar, chegando a produzir 38,7 milhões de toneladas de açúcar e 27,8 bilhões de litros de etanol na safra 2016/2017 (CONAB, 2017). A região Nordeste do Brasil é promissora para o setor sucroalcooleiro do país, por possuir área de expansão para a exploração da cultura e ainda ter um ótimo potencial climático (radiação solar), já que a cana-de-açúcar é bastante exigente em luz e água. Porém, as condições hídricas naturais limitam a produção da cultura sob regime de sequeiro. O total anual de precipitação aliado a sua má distribuição não atende plenamente as necessidades hídricas da cultura, tornando essencial o uso de irrigação complementar nos períodos onde há déficit hídrico no solo.

Para a adequada suplementação hídrica com o emprego da irrigação torna-se necessário a quantificação da demanȩ da hídrica da cana-de-açúcar, nos seus diferentes estádios de desenvolvimento. A análise de crescimento é uma forma acessível e precisa, que possibilita a avaliação e mensuração do desenvolvimento morfofisiológico das plantas, acompanhando seu crescimento ao longo de todo o ciclo.

A estimativa da demanda hídrica por meio do balanço de energia permite a quantificação dos fluxos de radiação líquida, de calor latente, de calor sensível e de calor do solo para se determinar a evapotranspiração da cultura (ETc), bem como em qual proporção cada componente contribui 


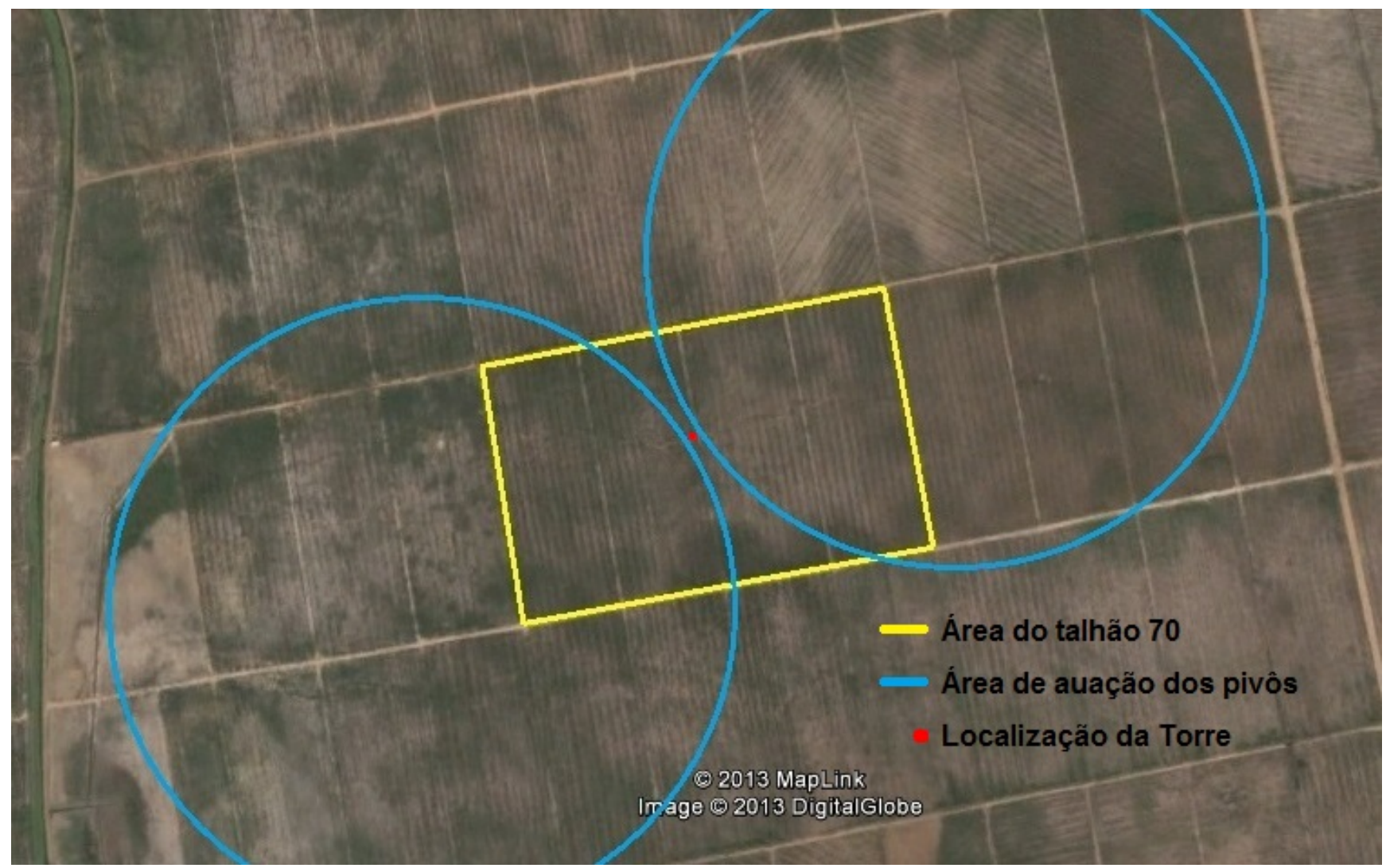

Figura 1. Área irrigada pelos pivôs centrais. Fonte: Google Earth.

para o processo de evapotranspiração. 0 método do balanço de energia, com base na razão de Bowen, utilizado para a quantificação dos fluxos de calor sensível (causador do aquecimento do ar) e de calor latente (responsável pelos processos de evapotranspiração), exige dois pré-requisitos básicos: o aporte de umidade considerável no sistema e uma bordadura com dimensões elevadas o suficiente para minimizar ao máximo o efeito advectivo calorífico e do vento.

É importante destacar que há carência de estudos na microrregião de Teresina, Piauí, visando a determinação da demanda hídrica da cana-de-açúcar, especialmente, usando o método do balanço de energia, tornando esse estudo de fundamental importância para a adequada estimativa das necessidades hídricas da cultura na região.

Diante do exposto, o objetivo geral do trabalho foi determinar a demanda hídrica da cultura da cana-de-açúcar por meio do método do balanço de energia, com base na razão de Bowen, na microrregião de Teresina, Piauí.

\section{Material e métodos}

O ensaio foi conduzido em um talhão comercial, com área de aproximadamente 10 ha, pertencente à Usina COMVAP - Açúcar e Álcool Ltda. (Figura 1), situada no município de União, na microrregião de Teresina, região centro-norte do Estado do Piauí, cujas coordenadas geográficas são as seguintes: latitude $4^{\circ} 52^{\prime} 49,56^{\prime \prime}$, longitu- de $42^{\circ} 53^{\prime} 07,56^{\prime \prime} \mathrm{W}$ e 67 metros de altitude. A precipitação pluviométrica média anual é de $1.343,4 \mathrm{~mm}$, sendo que os maiores índices são registrados nos meses de janeiro a abril. o clima da região, segundo a classificação de Thornthwaite e Mather (1955), é do tipo C1sA'a' (subúmido seco, megatérmico, com excedente hídrico moderado no verão) (BASTOS; ANDRADE JÚNIOR, 2014).

O solo da área onde foi implantado o experimento é classificado como um Argilossolo de coloração vermelho-amarela, cujas características químicas e físico-hídricas são apresentadas nas Tabela 1 e 2.

A curva característica de água no solo ajustada segundo o modelo de Genuchten (1980) é apresentada na Figura 2. Para a avaliação da dinâmica da água no solo usou-se um equipamento TDR, programado para efetuar e armazenar as leituras a cada $\mathbf{3 0}$ minutos. Foram instaladas sondas de aço inox, com $0,3 \mathrm{~m}$ de comprimento, em duas profundidae des $(0,0-0,3 \mathrm{~m}$ e $0,3-0,6 \mathrm{~m})$. As sondas foram instaladas a 0,2 $\mathrm{m}$ da fileira de plantas. 0 monitoramento estendeu-se dos 98 dias aos 235 dias após o corte do ciclo anterior (DAC).

Para a avaliação da dinâmica da água no solo usou-se um equipamento TDR, programado para efetuar e armazenar as leituras a cada 30 minutos. Foram instaladas sondas de aço inox, com $0,3 \mathrm{~m}$ de comprimento, em duas profund didades (0,0-0,3 $\mathrm{m}$ e 0,3-0,6 m). As sondas foram instaladas a $0,2 \mathrm{~m}$ da fileira de plantas. 0 monitoramento estendeu-se dos 98 dias aos 235 dias após o corte do ciclo anterior (DAC). 
Tabela 1. Características químicas de um Argissolo Vermelho-Amarelo, cultivado com cana-de-açúcar, na microrregião de Teresina (1ª soca), Piauí. 2013/2014.

\begin{tabular}{|c|c|c|c|c|c|c|c|}
\hline \multirow{3}{*}{ Camadas } & \multicolumn{7}{|c|}{ Análise química } \\
\hline & \multirow{2}{*}{$\mathrm{pH}$} & \multirow{2}{*}{$\begin{array}{l}\text { Fósforo } \\
\left(\mathrm{mg} / \mathrm{dm}^{-3}\right)\end{array}$} & Cálcio & Magnésio & Nitrogên & M.O. & \multirow{2}{*}{ CTC } \\
\hline & & & \multicolumn{2}{|c|}{$\left(\mathrm{cmol} \mathrm{dm}^{-3}\right)$} & \multicolumn{2}{|c|}{$\left(\right.$ dag $\left.\mathrm{kg}^{-3}\right)$} & \\
\hline $0-0,2 \mathrm{~m}$ & 7,20 & 8,89 & 3,77 & 1,34 & 0,05 & 1,34 & 5,11 \\
\hline $0,2-0,4 \mathrm{~m}$ & 6,68 & 6,86 & 0,53 & 0,61 & 0,02 & 0,58 & 1,14 \\
\hline $0,4-0,6 \mathrm{~m}$ & 6,01 & 7,93 & 0,22 & 0,43 & 0,03 & 0,56 & 0,66 \\
\hline Perfil & 6,63 & 7,89 & 1,51 & 0,79 & 0,03 & 0,83 & 2,30 \\
\hline
\end{tabular}

Tabela 2. Características físico-hídricas e granulométricas de um Argissolo Vermelho-Amarelo, cultivado com cana-de-açúcar (1ª soca), na microrregião de Teresina, Piauí. 2013/2014.

\begin{tabular}{|c|c|c|c|c|c|c|c|}
\hline \multirow{3}{*}{$\begin{array}{c}\text { Camadas } \\
\text { (m) }\end{array}$} & \multicolumn{3}{|c|}{ Análise físico-hídrica } & \multicolumn{4}{|c|}{ Análise granulométrica } \\
\hline & $\mathrm{CC}$ & PMP & \multirow{2}{*}{$\begin{array}{c}\text { Ds } \\
\left(\mathrm{Mg} \mathrm{m}^{-3}\right)\end{array}$} & Areia & Silte & Argila & Classificação \\
\hline & \multicolumn{2}{|c|}{$\left(\mathrm{m}^{3} \mathrm{~m}^{-3}\right)$} & & \multicolumn{3}{|c|}{$\left(\mathrm{g} \mathrm{kg}^{-1}\right)$} & textural \\
\hline $0,0-0,2$ & 0,23 & 0,05 & 1,57 & 806 & 100 & 94 & Areia-franca \\
\hline $0,2-0,4$ & 0,20 & 0,06 & 1,73 & 824 & 56 & 120 & Areia-franca \\
\hline $0,4-0,6$ & 0,19 & 0,08 & 1,69 & 765 & 39 & 196 & Franco-arenosa \\
\hline Perfil & 0,21 & 0,06 & 1,66 & 798,3 & 65 & 136,7 & Areia-franca \\
\hline
\end{tabular}

CC - Capacidade de campo; PMP - Ponto de murcha permanente; e Ds - Densidade aparente do solo.

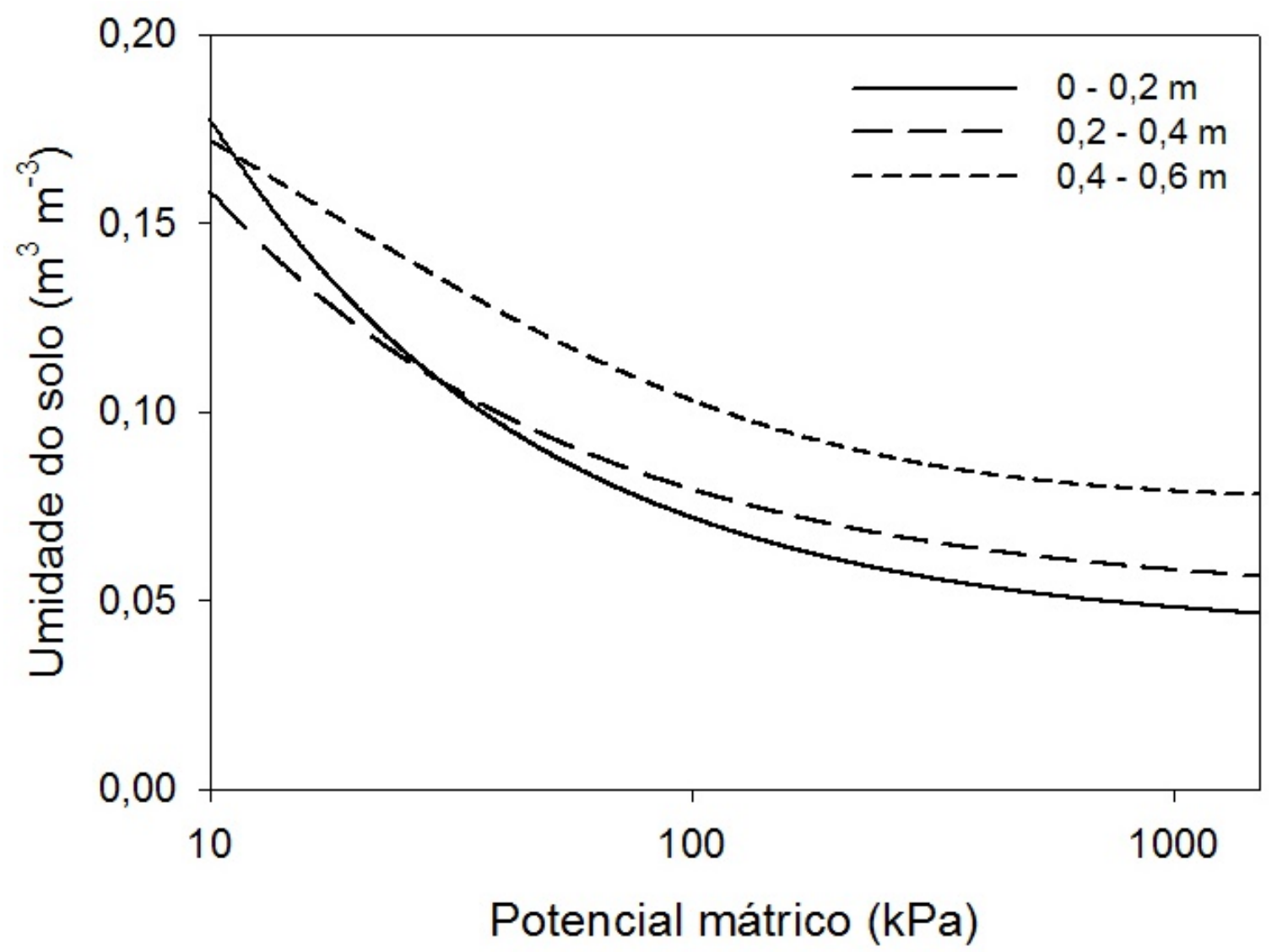

Figura 2. Curva característica de retenção de água em um Argissolo Vermelho-Amarelo, cultivado com cana-de-açúcar (1ª soca), na microrregião de Teresina, Piauí. 2013/2014. 
Tabela 3. Fases de desenvolvimento fenológico da cultivar RB867515 de cana-de-açúcar (1ª soca), na microrregião de Teresina, Piauí. 2013/2014.

\begin{tabular}{lccc}
\hline $\begin{array}{c}\text { Estádio fenológico } \\
\text { (Característica morfofisiológica) }\end{array}$ & Período & DAC & $\begin{array}{c}\text { Duração } \\
\text { (dias) }\end{array}$ \\
\hline I (Brotação e estabelecimento) & $18 / 07 / 2013$ a 16/09/2013 & 0 a 60 & 60 \\
II (Perfilhamento e crescimento) & $17 / 09 / 2013$ a 12/01/2014 & 61 a 178 & 118 \\
III (Máximo desenvolvimento) & $13 / 01 / 2014$ a 13/07/2014 & 179 a 360 & 182 \\
IV (Maturação) & $14 / 07 / 2014$ a 28/11/2014 & 361 a 498 & 138 \\
\hline Ciclo & $18 / 07 / 2013$ a 28/11/2014 & 0 a 498 & 498 \\
\hline
\end{tabular}

DAC: dias após o corte do ciclo anterior.

A cultivar de cana-de-açúcar avaliada no experimento foi a RB867515, ciclo de cana-soca ( $2^{\text {a }}$ folha), durante o ano agrícola 2013/2014, compreendendo um período total de aproximadamente 16 meses. Foi utilizado espaçamento em fileiras duplas de 1,4 $\mathrm{m}$ x 0,9 $\mathrm{m}$ x 2,3 $\mathrm{m}$. O corte do $1^{\circ}$ ciclo ocorreu em 18 de julho de 2013 e a colheita do ciclo em estudo foi realizada no dia 28 de novembro de 2014. Os tratos culturais (preparo de solo, adubação, calagem, aplicação de defensivos, irrigação, dentre outros) dispensados ao ensaio foram os mesmos adotados no sistema de produção da própria Usina.

As fases de desenvolvimento fenológico da cultura foram divididas conforme recomendação da Organização das Nações Unidas para a Alimentação e a Agricultura-FAO (ALLEN et al., 1998) as quais se encontram descritas na Tabela 3 .

Para obtenção dos dados climáticos necessários para a estimativa da ETo foi utilizada uma estação agrometeorológica automatizada, situada próximo à área experimental, que contém os seguintes sensores: termohigrômetro (temperatura e umidade relativa do ar), anemômetro (velocidade do vento) e piranômetro (radiação solar global incidente), com os quais procedeu-se a estimativa da evapotranspiração de referência (ETo) diária, por meio da equação de Penman-Monteith (ALLEN et al., 1998). A estação possui também um pluviômetro para quantificação da precipitação.

Para a estimativa dos fluxos necessários para o método do balanço de energia com base na razão de Bowen e consequentemente da evapotranspiração da cultura da cana-de-açúcar (ETC), foi utilizada uma torre de balanço de energia (Figura 3), situada aproximadamente no centro do talhão experimental (Figura 1). Para essa estimativa, foram utilizados os dados de fluxos obtidos no ano agrícola 2013/2014, sendo possível a instalação dos equipamentos em campo aos 83 DAC e ocorrendo a retirada dos mesmos aos 488 DAC, dez dias antes da colheita. Os equipamentos ficaram em funcionamento, no campo experimental de
09/10/2013 a 18/11/2014.

Para a estimativa dos componentes do balanço de energia foram utilizados psicrômetros ventilados com termopares do Tipo "T" de cobre-constantan, sendo o primeiro localizado a uma altura de $1 \mathrm{~m}$ do topo do dossel da cultura, enquanto o segundo a uma distância de 1,5 m do primeiro psicrômetro. Cada psicrômetro era composto por dois termopares: um de bulbo seco e outro de bulbo úmido. O termopar de bulbo úmido era conectado a um recipiente plástico, por meio de um cadarço de algodão.

As distâncias entre os psicrômetros foram mantidas até o final do experimento, bem como a distância entre o primeiro psicrômetro e a cultura, sendo estes, reposicionados para cima, semanalmente, por ventura do crescimento da cultura. Os recipientes plásticos, para umedecimento dos termopares úmidos, foram mantidos sempre com nível elevado de água destilada. O ajuste das distâncias das hastes dos psicrômetros e da água dos recipientes plásticos foi realizado por funcionário da usina.

Um saldo radiômetro, juntamente com um piranômetro, foram instalados à uma altura de $5 \mathrm{~m}$, em relação à superfície do solo, para medição dos componentes do balanço de radiação e para medição da radiação solar incidente, respectivamente. No topo da torre, foram dispostos dois painéis solares para a alimentação das baterias, que promovem o funcionamento eletrônico do sistema. Além disso, foi instalada uma bateria veicular de $12 \mathrm{~V}$ e $75 \mathrm{~A}$, para dar suporte suficiente à necessidade do sistema.

Para a estimativa da evapotranspiração da cultura (ETc) por meio do método de balanço de energia por Bowen Ratio (BERB) adotou-se o procedimento recomendado por Silva et al. (2012) e Carmo (2013). Para avaliar os erros associados com o método BERB na estimativa dos valores de $\beta$ e, consequentemente, no cálculo dos fluxos de calor latente (LE) e sensível (H), foi utilizada a metodologia desenvolvida por Perez et al. (1999). Os autores avaliaram a consistência física dos dados com base nos dados do perfil de pressão de vapor d'água em cada horário de medição, na 


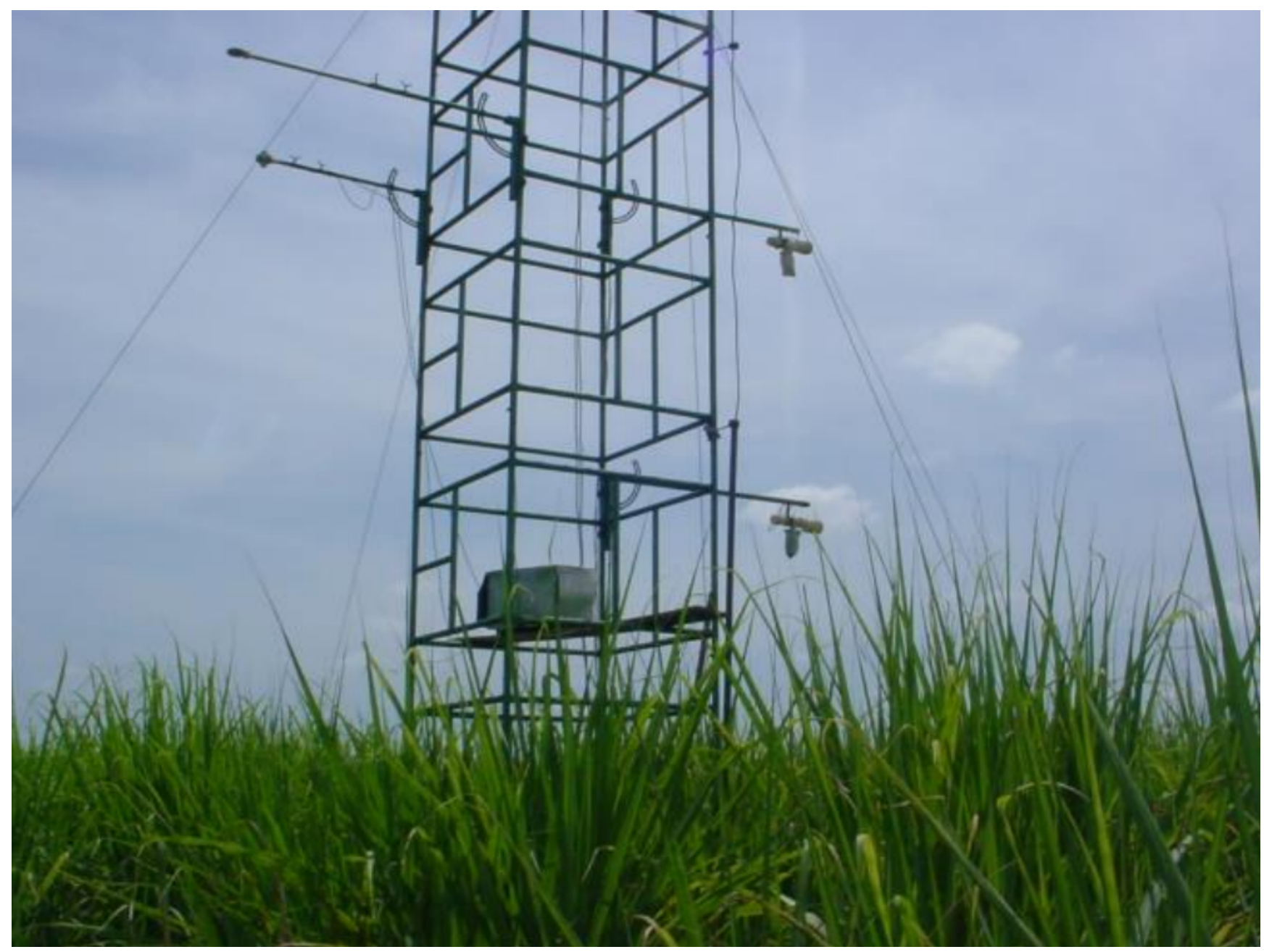

Figura 3. Torre micrometeorológica para medidas de elementos meteorológicos de balanço de energia da cultivar RB867515 de cana-de-açúcar (1ª soca), na microrregião de Teresina, Piauí. 2013/2014.

resolução dos sensores e na conversão de sinais da relação fluxo/gradiente (Tabela 4).

Tabela 4. Resumo dos erros do método do balanço de energia com base na razão de Bowen (BERB), segundo Perez et al. (1999).

\begin{tabular}{|c|c|}
\hline $\begin{array}{c}\text { Tipo de } \\
\text { Erro }\end{array}$ & Condição \\
\hline A & $(\mathrm{Rn}-\mathrm{G})>0, \Delta \mathrm{e}>\cdot, \beta<+1-|\varepsilon|$ \\
\hline $\mathrm{B}$ & $(\mathrm{Rn}-\mathrm{G})>0, \Delta \mathrm{e}<\cdot, \beta>1--|\varepsilon|$ \\
\hline $\mathrm{C}$ & $(\mathrm{Rn}-\mathrm{G})<0, \Delta \mathrm{e}>\cdot, \beta>1--|\varepsilon|$ \\
\hline $\mathrm{D}$ & $(\mathrm{Rn}-\mathrm{G})<0, \Delta \mathrm{e}<\cdot, \beta<+1-|\varepsilon|$ \\
\hline $\mathrm{E}$ & Mudanças rápidas de "T" e "e" \\
\hline
\end{tabular}

$\mathrm{Rn}$ - radiação solar líquida $\left(\mathrm{MJ} \mathrm{m}^{-2}\right) ; \mathrm{G}$ - fluxo de calor no solo $\left(\mathrm{MJ} \mathrm{m}^{-2}\right)$; De - déficit de pressão de vapor d'água $(\mathrm{kPa})$; $\beta$ - razão de Bowen; $\varepsilon$ - erro absoluto de $\beta$

Concluída a análise da qualidade física dos dados, com a remoção dos dados fisicamente inconsistentes, foi efetuado um ajuste estatístico dos dados, com o objetivo de remover-se ainda os valores de Kc considerados discrepantes. Para tanto, utilizou-se as medidas de dispersão: média e desvio padrão. Por esse critério, foram removidos os valores de ETc que eram inferiores à média menos o desvio padrão e superiores à média mais o desvio padrão.

\section{Resultados e discussão}

Considerando todo o período de avaliação da dinâmica de água no solo (dos 98 aos $235 \mathrm{DAC}$ ), em apenas 29 dias a água disponível (AD) apresentou-se abaixo da zona crítica estabelecida para cana-de-açúcar, conforme recomendado pela $\mathrm{FAO}$ (50\%), não restringindo o desenvolvimento e a demanda hídrica da cultura. Esse período concentrou-se na fase II, do início do monitoramento aos 100 DAC (24 a 26/10/2013) e dos 148 aos 172 DAC (13/12/2013 a 06/01/2014). Na fase II, o solo encontrava-se em torno de $30 \%$ de AD para a cultura, chegando próximo da capacidade de campo aos 106 DAC, mantendo-se assim acima da zona crítica até os 137 DAC. Dos 148 aos 173 DAC, a AD atingiu o mínimo de $29,4 \%$ (171 DAC), e a média igual a $40,7 \pm 8,0 \%$. Isso pode ser explicado por esse período fazer parte da estação chuvosa da região, no qual ocorreu um veranico, e por estar no período das águas, a Usina não realizou irrigações regulares. Na Fase III, a variação da AD ocorreu 


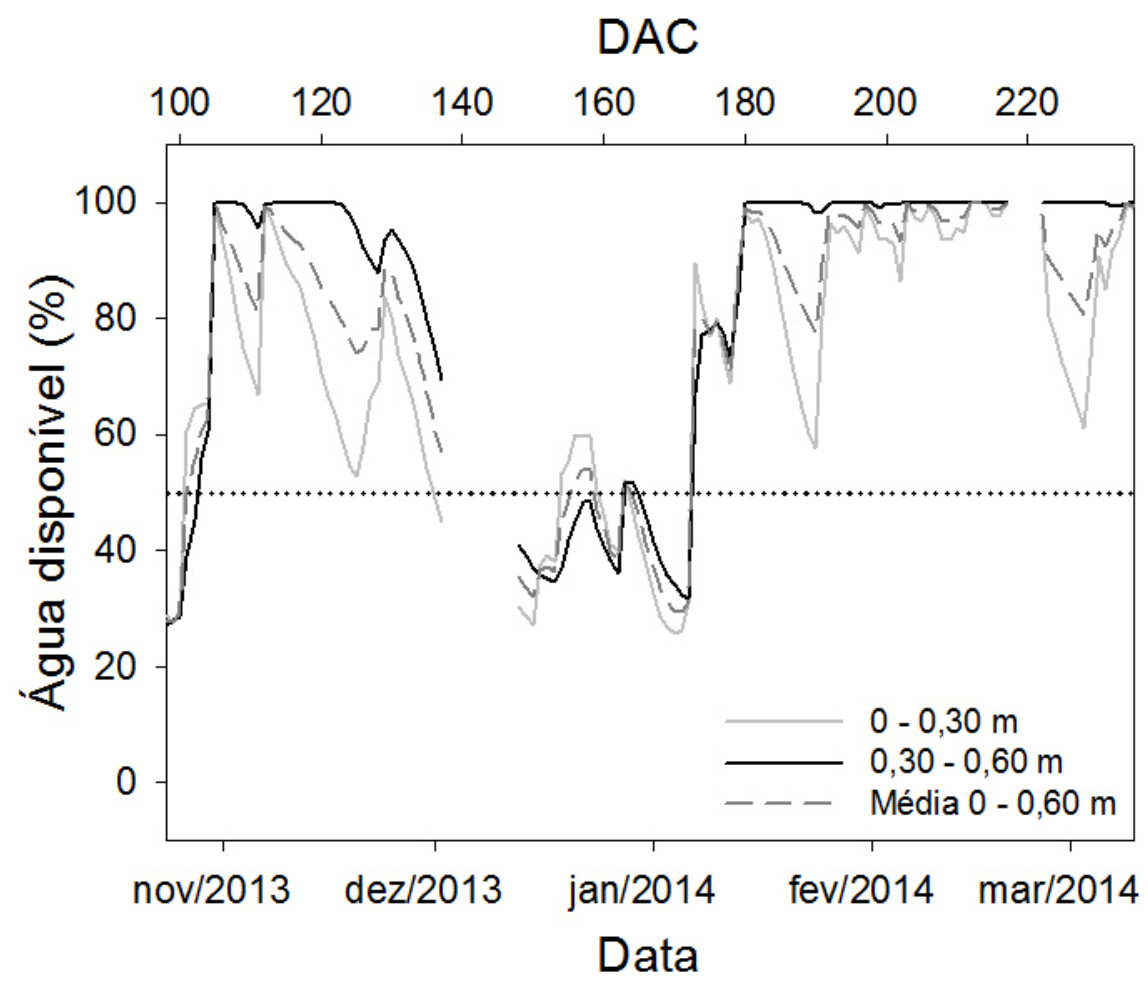

Figura 4. Conteúdo de água disponível à cultura da cana-de-açúcar (1ª soca), em um Argissolo Vermelho-Amarelo, na microrregião de Teresina, Piauí. 2013/2014.

sempre bem acima do ponto crítico, registrando os menores valores próximos de $80 \%$ e a média igual a $90,8 \pm 6,2 \%$ (Figura 4).

A análise de consistência física dos dados mostrou que a maioria dos erros encontrados foram caracterizados como do tipo B (95,5\%), se tratando do total dos 38.976 dados registrados, em que $22,48 \%$ deles apresentou-se erro do tipo B. Não foi detectado erros dos tipos C e D, que podem ocorrer em condição noturna. Erros do tipo A foram encontrados em proporções dentro do comum, perfazendo uma média de $0,27 \%$ (Tabela 5).

Valores semelhantes foram relatados por Silva et al. (2012), estudando a demanda da cana-de-açúcar no Submédio do Vale do São Francisco, por balanço de energia, com base na Razão de Bowen, que obteve $0,2 \%$ dos dados inconsistentes. Os dados de Razão de Bowen inferiores a $-0,75(\beta<-07,5)$ ocorreram em $0,78 \%$ do total amostral, variando de 0,74 a 0,85 nas fases de desenvolvimento. Silva (2011) constatou $0,4 \%$ de dados rejeitados, ao longo do ciclo de cultivo de cana-de-açúcar ( $1^{\mathrm{a}}$ soca).

Ao todo, foram avaliados, em 406 dias ao longo do ciclo de cultivo, 38.976 dados médios de $15 \mathrm{~min}\left(96 \mathrm{dia}^{-1}\right)$, onde foram classificados como inconsistentes, 5,06\%. A fase IV foi a que obteve relativamente, menos inconsistência física nos dados em geral (1,3\%), assim como em cada tipo de erro, especificamente. Dos 406 dias monitorados, 33,86\% foram caracterizados como válidos. Percentual bem abaixo do encontrado por Carmo (2013), que ao trabalhar com cana-de-açúcar no semiárido do Nordeste brasileiro, alcançou 77\% de dias válidos. O percentual baixo de dias válidos foi motivado pela ocorrência de muitos dias invalidados decorrentes da significativa presença do erro tipo $B$.

A evapotranspiração diária da cana-de-açúcar (ETc) e de referência (ETo), durante todo o ciclo de cultivo, atingiram médias iguais a 5,31 $\pm 1,02$ e 4,78 $\pm 1,03 \mathrm{~mm}$, respectivamente (Figura 5), mostrando que a demanda hídrica da cultura é superior à da cultura hipotética, tida como referência.

Na Fase I (brotação e estabelecimento da cultura), a ETo tomou-se crescente por aproximar-se do período com registros de temperaturas mais elevadas, na região (mês de outubro), no entanto não se registrou dados de ETc porque os equipamentos para registro desse parâmetro ainda não tinham sido instalados no campo experimental, sendo possível a quantificação da ETc somente a partir dos 98 DAC.

$\mathrm{Na}$ fase em que a cultura atinge seu crescimento mais acelerado (Fase II), iniciou-se o monitoramento das variáveis micrometeorológicas utilizadas na estimativa da ETc, por meio de balanço de energia, baseado na Razão de Bowen. Os valores de ETc nesta fase concederam uma média diária de 5,03 $\pm 1,21 \mathrm{~mm}$, variando de 1,96 a 6,8 $\mathrm{mm}$ por dia. Carmo (2013) quantificando, por Razão de Bowen, a 
Tabela 5. Análise de consistência física dos dados de Razão de Bowen, em cada estádio de desenvolvimento, ao longo do ciclo de cultivo da cana-de-açúcar, na microrregião de Teresina, Piauí. 2013/2014.

\begin{tabular}{lccccccccc}
\hline \multicolumn{1}{c}{$\begin{array}{c}\text { Fases } \\
\text { Fenológicas } \\
\text { (N. de dias) }\end{array}$} & $\begin{array}{c}\text { Dados } \\
\text { Inconsistentes } \\
(\%)\end{array}$ & $\mathrm{A}$ & $\mathrm{B}$ & $\mathrm{C}$ & $\mathrm{D}$ & $\beta<-0,75$ & $\begin{array}{c}(-1-|\varepsilon|) \\
<\beta< \\
(-1+|\varepsilon|)^{*}\end{array}$ & $\begin{array}{c}\text { Dias } \\
\text { Válidos } \\
(\%)^{* *}\end{array}$ \\
\hline F2 (96) & 6,74 & 0,40 & 29,24 & 0,0 & 0,0 & 0,85 & 9,94 & 14,29 \\
F3 (182) & 6,82 & 0,33 & 31,72 & 0,0 & 0,0 & 0,77 & 8,11 & 10,27 \\
F4 (128) & 1,30 & 0,07 & 3,18 & 0,0 & 0,0 & 0,74 & 3,83 & 82,11 \\
\hline Ciclo (406) & 5,06 & 0,27 & 22,14 & 0,0 & 0,0 & 0,78 & 7,29 & 33,86 \\
\hline
\end{tabular}

Obs.: *Considerando o total do número de dados obtidos (38.976); ${ }^{* *}$ Considerando o total de dias monitorados (406); Tipos de erro: "A" $=(\mathrm{Rn}-\mathrm{G})>0, \Delta \mathrm{e}>0, \beta<+1-|\varepsilon| ; " B "=(\mathrm{Rn}-\mathrm{G})>0, \Delta \mathrm{e}<0, \beta>1--|\varepsilon| ; " \mathrm{C} "=(\mathrm{Rn}-\mathrm{G})<0, \Delta \mathrm{e}>0, \beta>1--|\varepsilon| ; \mathrm{e}$ "D" $=(\mathrm{Rn}-\mathrm{G})<0, \Delta \mathrm{e}$ $<0, \beta<+1-|\varepsilon|$.

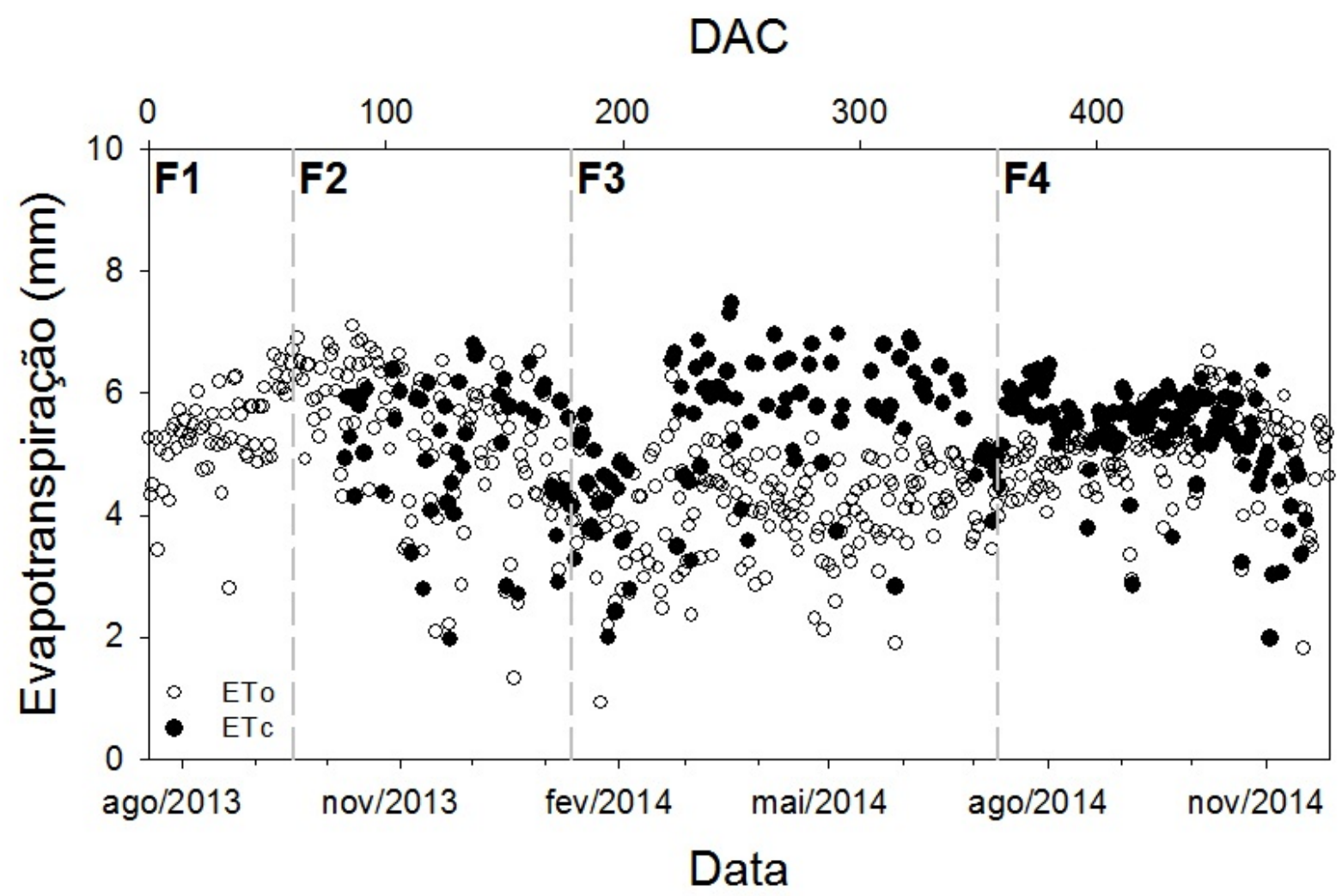

Figura 5. Valores, em escala diária, de evapotranspiração de referência e da cultura, ao longo do ciclo de cultivo da cana-de-açúcar, na microrregião de Teresina, Piauí. 2013/2014.

ETc da cana-de-açúcar, no Submédio do Vale do São Francisco, encontrou, para a mesma fase, valores diários alter-

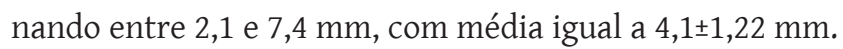
Apesar da ETc diária do autor flutuar em valores superiores aos encontrados nesse trabalho, sua média tornou-se inferior por terem ocorrido mais dias nublados, com menor disponibilidade de saldo de radiação que nas condições do presente estudo. A alta variação de ETc deste trabalho, para a fase II, deve-se ao fato de coincidir com o início do período das chuvas, quando há dias ensolarados e outros nublados (e/ou chuvosos).
Na Fase III, que a cultura possui maior demanda hídrica, é perceptível que o conjunto de pontos referentes à ETc, oscilando de 1,99 a 7,47 mm, localiza-se acima do conjunto de dados da ETo, expondo a confirmação de que a exigência em água, da cana-de-açúcar $\left(5,24 \pm 1,27 \mathrm{~mm} \mathrm{dia}^{-1}\right)$, é superior à da cultura referência $\left(4,14 \pm 0,8 \mathrm{~mm} \mathrm{dia}^{-1}\right)$ nessa fase.

A fase de maturação fisiológica da cultura (Fase IV) proporciona um decréscimo no seu requerimento d'água, porém nessa fase, os valores de ETc mostraram-se levemente maiores aos da fase anterior, tomando uma média diária 


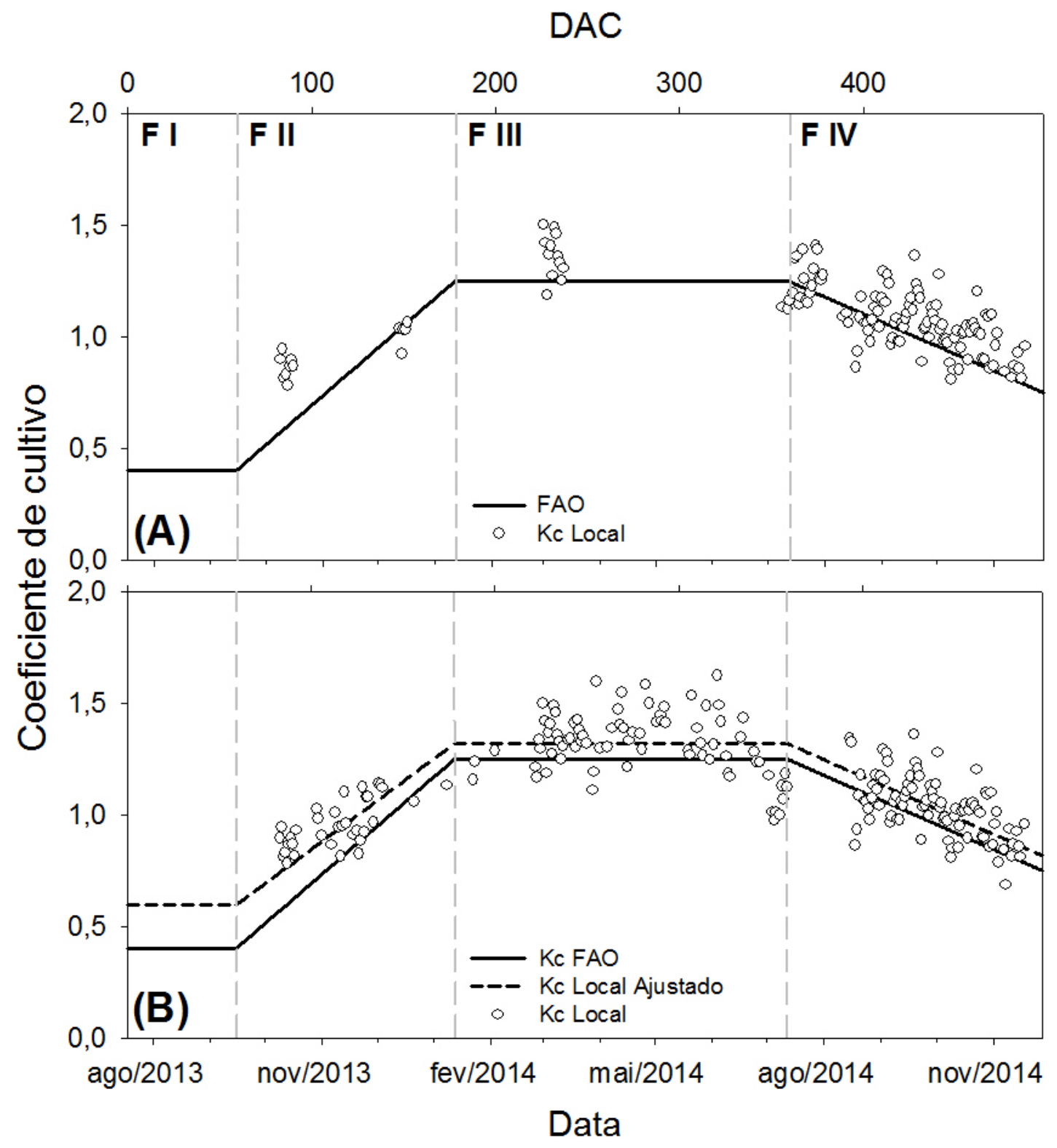

Figura 6. Valores, em escala diária, ao longo do ciclo, do coeficiente de cultivo (Kc) da cana-de-açúcar recomendado pela FAO e obtido por balanço de energia com base na Razão de Bowen, para os dias considerados válidos (A) e todos os dias monitorados, bem como Kc ajustado (B), para a microrregião de Teresina, Piauí. 2013/2014.

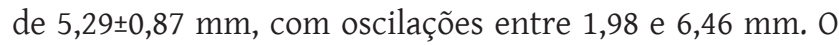
suave aumento médio da ETc foi ocasionado pela elevação da média diária de ETo $(4,98 \pm 0,77 \mathrm{~mm})$. o desvio padrão da amostra de ETc nessa fase apresentou uma redução, quando comparado com as anteriores, porque a grande maioria dos dias permaneceram parcialmente ensolarados, restando poucos dias nublados ou parcialmente nublados.

Os valores diários do coeficiente de cultivo (Kc) para a cultura da cana-de-açúcar em função do número de dias após o corte (DAC) apresentaram média igual a 1,13 $\pm 0,19$ (Figura 6). Em trabalho realizado na região costeira da Paraíba, com cana-de-açúcar de primeira soca, Silva et al. (2012) mensuraram o Kc da cultura, obtendo média para o ciclo de 0,9, inferior à do presente estudo; no entanto, considerando apenas as fases de rápido crescimento (F II), maior demanda hídrica (F III) e maturação (F IV), tal como realizada neste trabalho, a média ajustada do Kc foi igual a 1,08 .

Percebe-se que há três intervalos de tempo onde inexistem apontamentos de Kc por Razão de Bowen, já que foram dias considerados inválidos (Figura 6A); apesar disso, ao serem inseridos, nota-se que esses dados, mesmo que considerados fisicamente inválidos (Figura 6B), têm um desempenho coerente, não tomando-se discrepantes dos considerados válidos, o que significa que os erros decorrentes invalidaram apenas a parte físico-matemática do processo, desconsiderando, parcialmente, a resposta fisiológica da planta à demanda evapotranspirativa da atmosfera.

Até os 60 DAC (Fase I), a demanda da cultura por água ainda é baixa (decorrente da própria cultura, que ainda está rebrotando e pouco desenvolvida), nessa fase o Kc 
adotado pela FAO porta-se fixo, igual a 0,4 e ajustada nas condições do presente trabalho em 0,6. Na Fase II, como o crescimento da cultura revela-se acelerado, o Kc torna-se progressivo, com valores de 0,88 a 1,19, com média, até os 180 DAC igual a $0,9 \pm 0,13$. Win, Zamora e Thein (2014) encontraram valores inferiores de Kc, na fase de rápido desenvolvimento (média de 0,81), na região de Pyinmana, Myanmar, no sul da Ásia continental. Por outro lado, Silva et al. (2012), ao avaliar cultivar de ciclo médio-tardio, nas condições climáticas semiáridas do Submédio São Francisco, obtiveram valores de Kc mais aproximados aos obtidos no presente estudo, embora que ainda um pouco inferiores, obtiveram para essa fase, aumento no Kc de 0,85 para 1,0 . Nesta mesma fase obteve-se valores mais altos que os dos demais autores, por não ter sido monitorado o período inicial, no qual encontram-se, em teoria, os menores valores de Kc, o que elevou a estimativa do Kc médio da fase II.

Na Fase III, quando a cultura atinge seu máximo crescimento vegetativo e requerimento hídrico, obteve-se Kc

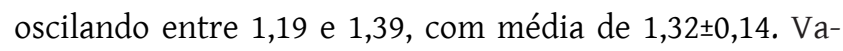
lores de Kc inferiores foram obtidos por Inman-Bamber e McGlinchey (2003) e Win, Zamora e Thein (2014), que ao estimar o Kc da cana-de-açúcar, por Razão de Bowen, no Distrito de Burdekin, nordeste da Austrália, e em Pyinmana, Myanmar, respectivamente, obtiveram valor médio de Kc na fase III igual a 1,25, tal como recomenda a FAO. O Kc encontrado neste estudo foi superior, quando comparado com os autores citados e a FAO, porque as condições climáticas locais possuem maior poder evapotranspirativo.

Na Fase IV, por fundamento fisiológico da cana-de-açúcar, a necessidade hídrica tende a diminuir até a colheita. Assim, o Kc da cultura reduziu de 1,2 até atingir

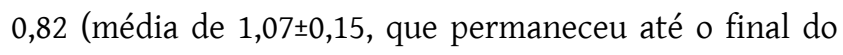
ciclo de cultivo, valor superior ao recomendado pela FAO $(0,75)$. Iaia (2014), ao avaliar cultivares de cana-de-açúcar, inclusive a RB867515, em São José do Rio Claro, no cerrado mato-grossense, encontrou na fase de maturação valores de Kc próximos aos deste trabalho, com variação de Kc de 1,1 a 0,8 .

A evapotranspiração da cultura da cana-de-açúcar variou ao longo do ciclo de cultivo de 1,96 a $7,47 \mathrm{~mm}$, perfazendo uma média de 5,31 $\pm 1,03 \mathrm{~mm}$. Nassif, Marin e Costa (2014), ao avaliar a $2^{\mathrm{a}}$ soca de cana-de-açúcar irrigada por gotejamento, em Piracicaba, São Paulo, encontrou uma média diária igual a 5,2 $\mathrm{mm}$, ao longo do ciclo de 365 dias.

\section{Conclusões}

A ETc média diária da cultura da cana-de-açúcar, cultivar RB867515, na microrregião de Teresina, foi igual a 5,03, 5,24 e 5,29 mm nas Fases II, III e IV, respectivamente, com média de 5,31 $\mathrm{mm} \mathrm{dia}^{-1}$ ao longo do ciclo.

O coeficiente de cultura (Kc) foi igual a 0,9 na fase de rápido crescimento (61 a $178 \mathrm{DAC}), 1,32$ na fase de máximo desenvolvimento (189 a 360 DAC) e 1,07 na fase de maturação fisiológica (361 a 498 DAC).

\section{Agradecimentos}

À Usina COMVAP pela disponibilidade da área experimental e de mão-de-obra para a condução do experimento de campo. À CAPES pela concessão da bolsa de mestrado, fundamental nessa caminhada e conclusão do trabalho.

\section{Referências}

ALLEN, R. G.; PEREIRA, L. S.; RAES, D.; SMITH, M. Crop evapotranspiration: guidelines for computing crop water requirements. Rome: FAO, 1998. (Irrigation and Drainage Paper, n. 56).

BASTOS, E. A.; ANDRADE JÚNIOR, A. S. Boletim Agrometeorológico de 2013 para o Município de Teresina, Piauí. Teresina: Embrapa MeioNorte, 2014. 38 p. (Embrapa Meio-Norte. Documentos, 228).

CARMO, J. F. A. Evapotranspiração da cana-de-açúcar irrigada por gotejamento subsuperficial no Submédio do Vale do São Francisco. 2013. 84 f. Dissertação (Mestrado em Engenharia Agrícola) Universidade Federal do Vale do São Francisco, Juazeiro, 2013.

CONAB. Companhia Nacional de Abastecimento. Acompanhamento da safra brasileira de cana-de-açúcar: primeiro levantamento - Safra 2017/2018, v. 4, n. 1, 62p, abril/2017. Conab, 2017.

IAIA, A. M. Irrigação por gotejamento em cana-de-açúcar no cerrado de mato grosso. 2014. 128 f. Tese (Doutorado em Agronomia) Universidade Federal do Paraná, Curitiba, 2014.

GENUCHTEN, M.T.V. A closed form equation for predicting the hydraulic conductivity of unsaturated soils. Soil Science Society of American Journal, Madison, v.44, p.892-898, 1980.

INMAN-BAMBER, N. G.; MCGLINCHEY, M. G. Crop coefficients and wateruse estimates for sugarcane based on long-term Bowen ratio energy balance measurements. Field Crops Research, v. 83, n. 2, p. 125-138, 2003.

NASSIF, D. S. P.; MARIN, F. R.; COSTA, L. G. Evapotranspiration and transpiration coupling to the atmosphere of sugarcane in southern Brazil: scaling up from leaf to field. Irriga, v. 16, n. 3, p. 1-5, 2014.

PEREZ, P. J.; CASTELLVI, F.; IBAÑEZ, M.; ROSELL, J. I. Assessment of reliability of Bowen ratio method for partitioning fluxes. Agricultural and Forest Meteorology, Amsterdam, v. 97, p. 141-150, 1999.

SILVA, T. G. F. Análise de crescimento, interação biosfera-atmosfera e eficiência do uso de água da cana-de-açúcar irrigada no Submédio do Vale do São Francisco. 176f. Tese (Doutorado em Meteorologia Agrícola) - Universidade Federal de Viçosa, Viçosa. 2011.

SILVA, T. G. F.; MOURA, M. S. B.; ZOLNIER, S.; SOARES, J. M.; VIEIRA, V. J. S.; FARIAS JÚNIOR, W. G. Requerimento hídrico e coeficiente de cultura da cana-de-açúcar irrigada no Semiárido brasileiro. Revista Brasileira de Engenharia Agrícola e Ambiental, v. 16, n. 1, p.64-71, 2012.

THORNTHWAITE, C. W.; MATHER, J. R. The water balance. New Jersey: Laboratory of Climatology, 1955.86 p. (Publication in Climatology, v. 8, n. 1).

WIN, S. K.; ZAMORA, O. B.; THEIN, S. Determination of the water requirement and Kc values of sugarcane at different crop growth stages by lysimetric method. Sugar Tech, v. 16, n. 3, p. 286-294, 2014. 


\title{
Water demand of sugarcane, through the energy balance method, at Teresina region, Piauí State, Brazil
}

\author{
Aderson Soares de Andrade Junior ${ }^{1(*)}$, Donavan Holanda Noleto ${ }^{2}$, Edson Alves Bastos ${ }^{3}$, Magna Soelma Beserra de Moura ${ }^{4}$, \\ João Carlos Rocha dos Anjos ${ }^{5}$ \\ ${ }^{1}$ Pesquisador, Embrapa Meio-Norte, Teresina, PI, aderson.andrade@embrapa.br \\ ${ }^{2}$ Mestre em Engenharia Agrícola, UFC, Fortaleza, CE, donavan.noleto@outlook.com \\ ${ }^{3}$ Pesquisador, Embrapa Meio-Norte, Teresina, PI, edson.bastos@embrapa.br \\ ${ }^{4}$ Pesquisadora, Embrapa Semiárido, Petrolina, PE, mgna.moura@embrapa.br; 5Professor, UFPI, Bom Jesus, PI, joaocarlosrochadosanjos@hotmail.com \\ ${ }^{(*)}$ Autor para correspondência
}

\section{ARTICLE INFO}

\section{Article history:}

Received 16 June 2017

Accepted 10 August 2017

\section{Index terms:}

Saccharum officinarum L

crop coefficient

Bowen ratio

\section{ABSTRACT}

The objective of this study was to determine the water demand of sugarcane, through the energy balance method (Bowen ratio), at the Teresina region, Piauí State, Brazil. The experiment was conducted at COMVAP - Sugar and Alcohol Ltda., in the União County, at Teresina region, Piauí. The cultivar used was RB867515, irrigated by center pivot. To estimate crop evapotranspiration (ETC) was used an equipped tower with microelectronic sensors installed in the center of the growing area (10 ha plot). The reference evapotranspiration (ETo) was estimated by the Penman-Monteith method. The physical consistency of the ETC analysis data showed that $33.9 \%$ of 406 days monitored were agreement. The ETc daily average was $5.3 \mathrm{~mm}$, with a demand of 2,650 $\mathrm{mm}$ for the 498 days of the cycle. The crop coefficient (Kc) average per phase was 0.9 (fast growth), 1.32 (maximum development) and 1.07 (maturation).

CITATION

Disclaimer: papers are published in this issue of AGROMETEOROS (v. 25, n.1, aug 2017) as accepted by the XX Congresso Brasileiro de Agrometeorologia, held August 14-18, 2017 in Juazeiro, Bahia and Petrolina, Pernambuco, Brazil, without further revision by editorial board.

REFERENCIAÇÃO

ANDRADE JUNIOR, A. S. de; NOLETO, D. H.; BASTOS, E. A.; MOURA, M. S. B. de; ANJOS, J. C. R. dos. Demanda hídrica da cana-de-açúcar, por balanço de energia, na microrregião de Teresina, Piauí. Agrometeoros, Passo Fundo, v.25, n.1, p.229-238, 2017.

Declaração: os trabalhos estão sendo publicados nesse número de AGROMETEOROS (v.25, n.1, ago 2017) conforme foram aceitos pelo XX Congresso Brasileiro de Agrometeorologia, realizado de 14 a 18 de agosto de 2017, em Juazeiro, BA e Petrolina, PE, sem revisão editorial adicional da revista. 